\title{
Interactive comment on "Can Limits to Growth in the Renewable Energy Sector be Inferred by Curve Fitting to Historical Data?” by Kristoffer Rypdal
}

\author{
dr. Rypdal \\ kristoffer.rypdal@uit.no \\ Received and published: 14 November 2017
}

Thanks for a useful and constructive review. All comments by the reviewer are timely and will be addressed in the revision if the editor invites a revision. Here is just some very preliminary responses.

A broader framing and discussion in the context of Earth System Dynamics will be included, although my intention still is to keep this paper short. A more extensive list of references in this direction will be included.

The reviewer questions whether the pedagogical structure and appeal of the paper is an appropriate style for a research article in Earth System Dynamics. To some extent I share this doubt, which is why I submitted it primarily as a short communication, only 
subsidiarily as a research article. According to ESD guidelines "Short Communications report particularly concise and innovative/controversial perspectives on the Earth system." I don't claim that my contribution is particularly innovative, but it is concise, I believe it is correct, and the subject is particularly controversial in the public as well as the scientific debate.

The uncertainty analysis for the cases considered in Section 3.2 and 3.3 can of course be included, although it will not reveal much new, and will require a couple of additional figures. I suggest that it be included in Supplementary Material, since this is intended to be a short paper.

Section 4 , p. 13, line $27 \mathrm{ff}$. Here only a rough estimate of the number of independent data points can be made, since the sample contains only 19 points. The number of independent points is based on a rough estimate of the autocorrelation time. Details will be presented in the Supplement.

Relevant references from the litterature on model selection will be included.

The codes for the analysis and production of the figures will be made available as a supplementary Mathematica notebook along with all data files used.

In figures, time will be given in years AD.

Interactive comment on Earth Syst. Dynam. Discuss., https://doi.org/10.5194/esd-2017-93, 2017. 